Document downloaded from:

http://hdl.handle.net/10251/72355

This paper must be cited as:

Capilla, C. (2016). Assesing Students Using Collaborative and Non-collaborative Activities in an Introductory Statistics Course. En INTED2016 Proceedings. IATED Digital Library. 57315737. doi:10.21125/inted.2016.0375.

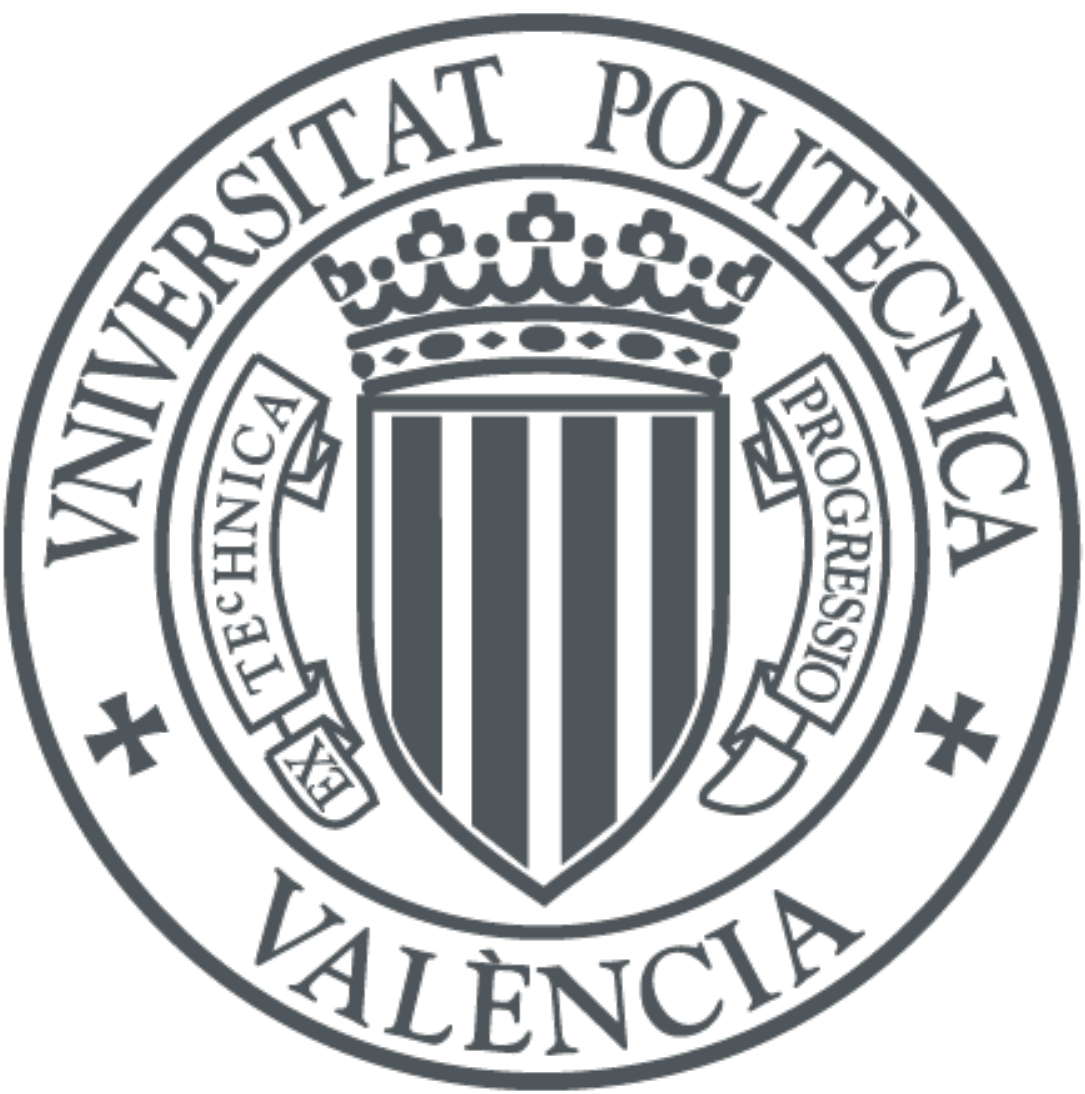

The final publication is available at

https://library.iated.org/publications/INTED2016

Copyright IATED Digital Library

Additional Information 


\title{
ASSESSING STUDENTS USING COLLABORATIVE AND NON- COLLABORATIVE ACTIVITIES IN AN INTRODUCTORY STATISTICS COURSE
}

\author{
Carmen Capilla ${ }^{1}$ \\ ${ }^{1}$ Polytechnic University of Valencia (SPAIN)
}

\begin{abstract}
This paper presents collaborative and non-collaborative assessment activities results in a statistics course of a bachelor's degree in computer science engineering. Simple regression models are evaluated in the classroom, in a computer laboratory session and in a final exam. The 2014_2015 academic year evaluations results are presented for a sample of 93 students of two different groups. The average marks obtained in the exam simple regression question, is worse than in the classroom and computer laboratory tasks in both groups. In one group there is linear correlation between the average marks in the classroom evaluation and the exam result. In the other group the correlation is significant between the three assessment activities.
\end{abstract}

Keywords: Collaborative activity, regression models, undergraduate students, informatics engineering.

\section{INTRODUCTION}

In this work the assessment activities and the students' performance in a simple regression unit taught in the academic year 2014_15, are presented. The students were involved in a bachelor's degree in informatics. They were in the degree's first year. An introduction to regression was taught in a face-toface compulsory statistics course in the second semester. The course contents were descriptive statistics, probability distributions, an introduction to inference, analysis of variance, and correlation and simple regression models. Section 2 gives the basic concepts explained in this last part, and the teaching methodology is presented. The assessment activities used to evaluate these contents are described in Section 3. Section 4 discusses the evaluations results.

\section{SIMPLE REGRESSION MODELS AND TEACHING METHODOLOGY}

In the statistic course of the computer science degree several methodologies are explained with an emphasis in their application in this field. The tools explained and evaluated have been chosen following the recommendations of several institutions [1]. The course was taught during the 15 weeks of the second semester of the academic year 2014_15. There were two sessions every week, that lasted 90 minutes, and took place in the classroom. In the ten laboratory classes, students' teams solved problems and used software in a length of time of 90 minutes.

The last part of the course was an introduction to regression models. According to the syllabus the contents of this unit were

- bivariate descriptive analysis (frequency tables, covariance, correlation and scatterplot),

- simple regression model assumptions,

- model coefficients interpretation,

- residuals analysis,

- inference on the model and its parameters,

- model evaluation (analysis of variance and coefficient of determination),

- model application to obtain predictions and intervals.

Some instructional goals described by [2], to achieve that students become "informed citizen" after the course, are:

- understanding of the existence of variation, 
-application of methods to display, explore, and analyze, by hand or using technologies, -connecting summary statistics and graphical representations,

-developing communications skills, and using statistical and probabilistic terminology properly.

The course teaching methodologies and assessments tried to achieve these goals. The bibliography recommended to the students consisted in several books, with an emphasis on computer science applications [3], statistics for engineers training [4], or for experimenters [5]. In the classroom lectures, the methods were explained with some examples of different contexts. A frequency table, a scatterplot and the correlation coefficient, were applied to students' weight and height data, obtained with a questionnaire [4], that they completed at the beginning of the course. This questionnaire was similar to an activity described in [6]. The dependence of daily gas consumption on average temperature in a factory ([4], [7]) was analysed using a scatterplot, the covariance matrix, the correlation coefficient and the regression model.

The computer laboratory activity had 11 questions [8] on the analysis of a data set (25 bivariate observations), related with the performance of a computer system. The relationship between the number of users and the run time of a benchmark program, was investigated using the methods explained in the lectures. Teams of two or three students had to complete the task, using statistical software and the formulas to compute parameters, and to connect their results with graphical representations. In the previous practice, students had represented the scatterplot, and answered questions on its interpretation and relation with covariance and correlation coefficient.

Table 1 shows some software output of the analysis that the activity requires. It includes the regression equation parameters (intercept and slope), the t-statistics and the p-value for their inference. The table also has the analysis of variance and R-squared to test the model goodness of fit. A $95 \%$ prediction interval is computed by hand. Fig. 1 gives the fitted linear equation and the corresponding $90 \%$ prediction intervals. The last question has the aim of validating this prediction by asking the residuals exploratory analysis. Summary statistics of prediction errors and its normal probability plot (Fig. 2) are applied to check the assumption of Gaussian distribution.

Table 1. Simple regression model output

Regression Analysis - Linear model: $Y=a+b^{*} X$

Dependent variable: RUN TIME

Independent variable: NUM̄BER_USERS

\begin{tabular}{lllll} 
& & Standard & $T$ & $T$ \\
Parameter & Estimate & Error & Statistic & P-Value \\
\hline Intercept & 1,04573 & 0,21043 & 4,96951 & 0,0001 \\
Slope & 0,736479 & 0,014546 & 50,6311 & 0,0000
\end{tabular}

Analysis of Variance

\begin{tabular}{lcclcc}
\hline Source & Sum of Squares & Df & Mean Square & F-Ratio & P-Value \\
\hdashline Model & 859,077 & 1 & 859,077 & 2563,51 & 0,0000 \\
Residual & 7,70771 & 23 & 0,335118 & & \\
\hline & & & &
\end{tabular}

Total (Corr.) $\quad 866,785 \quad 24$

Correlation Coefficient $=0,995544$

R-squared $=99,1108$ percent

Standard Error of Est. $=0,578894$ 


\section{Plot of Fitted Model}

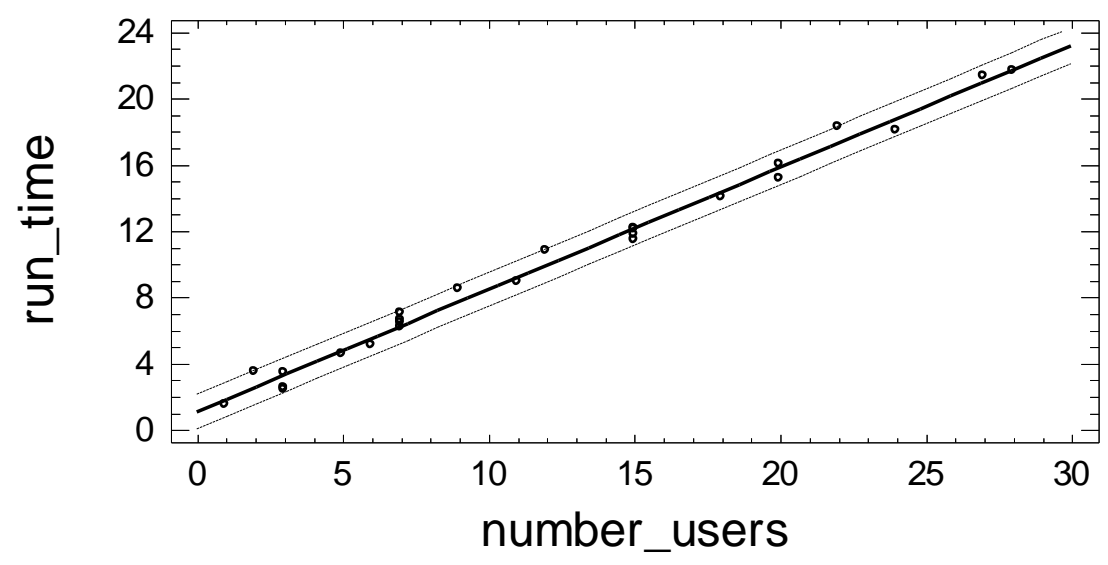

Figure 1. Linear regression model and $90 \%$ prediction intervals.

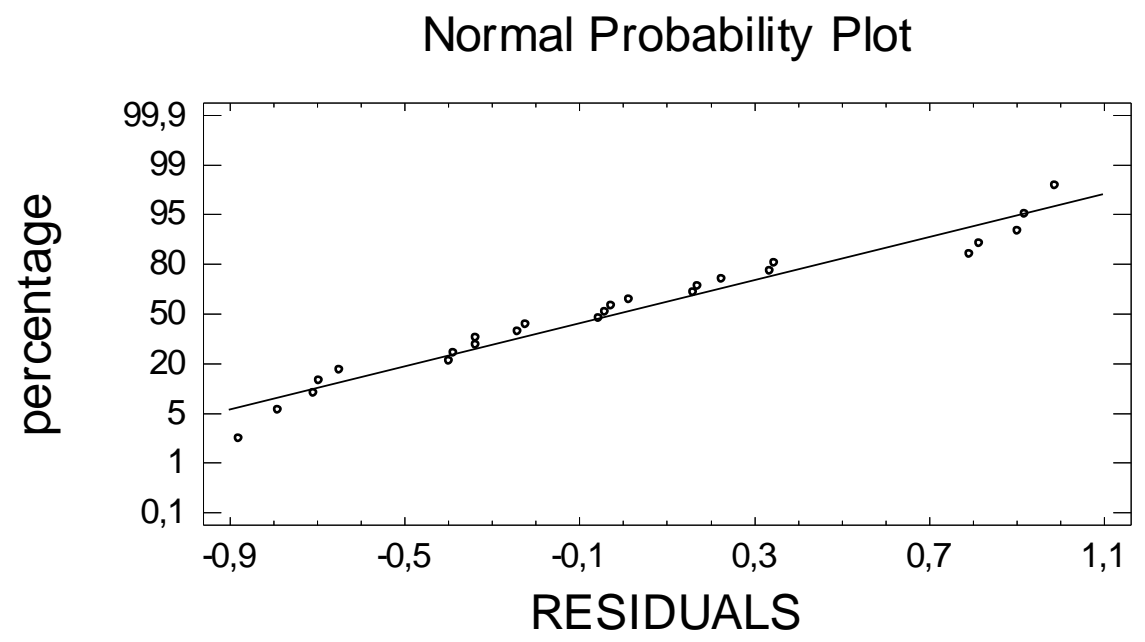

Figure 2. Normal probability plot of the regression model (Table1) residuals

\section{ASSESSMENT ACTIVITIES}

The introduction to regression unit was assessed in the classroom, in the computer laboratory session, and with a question in the exam at the end of the semester. The evaluation in the classroom was made after the explanation of the concepts enumerated in Section 2. It consisted of two exercises that were given to each student at the beginning of the evaluation session. During the assessment, that lasted between 60 to 45 minutes, they could look up in the course teaching materials, their notes, bibliography recommended for the course or any other information source. The activity could be collaborative or non-collaborative, with a consensus or a non-consensus approach. Each student presented a written answer. In the first exercise (proposed by other teacher another year), software output of a covariance matrix was presented, and four conclusions based on these analysis given. They had to indicate which conclusions were true, and justify the answers. 
The second exercise involved the application of formulas to estimate the intercept, and slope of a regression model, and a 95\% prediction interval. Students had to use the means and standard deviations of 13 daily observations of the workload and response time of a computer system. The data are in [9]. Fig. 3 represents the scatterplot matrix of the sample.

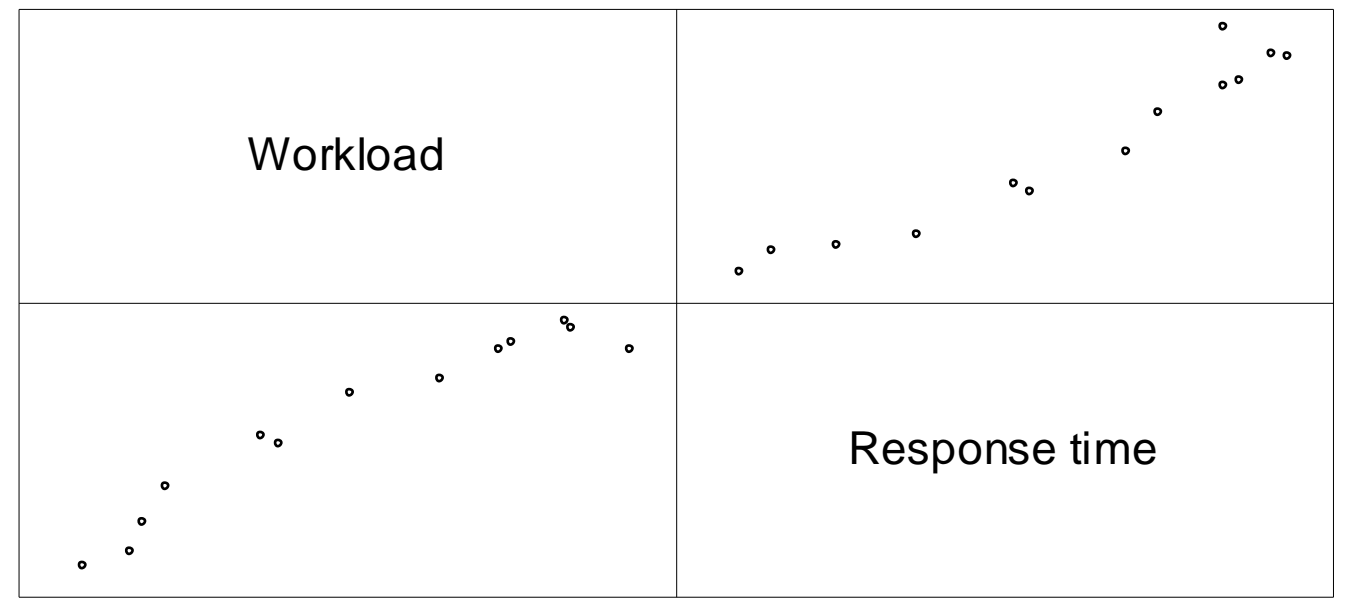

Figure 3. Scatterplot matrix of workload and response time.

Table 2 contains the Pearson product moment correlation between the two variables. Table 3 gives the summary statistics analysis.

Table 2. Correlation matrix of the evaluation data.

\section{Correlations}

\begin{tabular}{ccc} 
& WORKLOAD & RESPONSE TIME \\
\hline WORKLOAD & 0,9640 \\
& & $(13)$ \\
& 0,0000
\end{tabular}
RESPONSE TIME $\quad 0,9640$
$(13)$
0,0000

\section{Correlation \\ (Sample Size) \\ P-Value}

In the computer laboratory session, each team had to present written consensus answers to an evaluation task that involved a linear regression example. It was prepared by another teacher with printed output. Using this output, students were asked to write and estimate a model that established the dependence of height on age of a sample of 263 school children, with the techniques taught in the lectures and in the practice. The intercept and slope identification in the output, their interpretation and significance tests, and the conclusions of the model analysis of variance, were another assessment questions. They were asked to indicate the unexplained variance magnitude using the parameters in the output that quantified it. The application of the regression equation was evaluated by the estimation of a forecast error and a $99 \%$ prediction interval. The teams could consult any information material. 
The exam was at the end of the semester, and had a 5 questions problem on regression made up by another teacher. Each student in a non-collaborative way, had to answer it using the distribution tables and the list of statistical formulas, elaborated by the subject coordinator. The problem had software output on the application of a simple regression model to study the performance of a vector ordering algorithm. The explanatory variable was time (microseconds), and the response was vector size (500-800). The sample size was 28 observations. The instructional goals to be evaluated were: the application by hand of the tools explained in the classroom and in the computer laboratory, and the written communications skills using statistical terminology. Their answers were based on the parameter estimations and standard deviations, the intercept $p$-value, and the model, residuals and total sum of squares. They had to write the estimated model equation, and interpret its coefficients. This interpretation and the second question, implied the application of the significance t-test on the parameters. A 95\% prediction interval and the correlation coefficient had to be computed. The last part posed a question related with the covariance and correlation.

Table 3. Summary statistics for the variables

Summary Statistics

\begin{tabular}{|c|c|c|}
\hline \multicolumn{2}{|c|}{ WORKLOAD } & RESPONSE TIME \\
\hline Count & 13 & 13 \\
\hline Average & 5,59231 & 2,91538 \\
\hline Median & 5,5 & 3,3 \\
\hline Variance & 10,3258 & 1,45974 \\
\hline Standard deviation & 3,21337 & 1,2082 \\
\hline Minimum & 1,0 & 0,9 \\
\hline Maximum & 10,2 & 4,3 \\
\hline Range & 9,2 & 3,4 \\
\hline Lower quartile & 2,4 & 2,0 \\
\hline Upper quartile & 8,2 & 3,9 \\
\hline Interquartile range & 5,8 & 1,9 \\
\hline Stnd. skewness & $-0,0614087$ & $-0,788795$ \\
\hline Stnd. kurtosis & $-1,19011$ & $-0,895607$ \\
\hline
\end{tabular}

\section{RESULTS AND DISCUSSION}

The evaluation activities were completed by 93 students of two different groups, with the same teacher. Fig. 4 includes the scatterplots and box-whiskers of the students' marks in the three assessment activities.

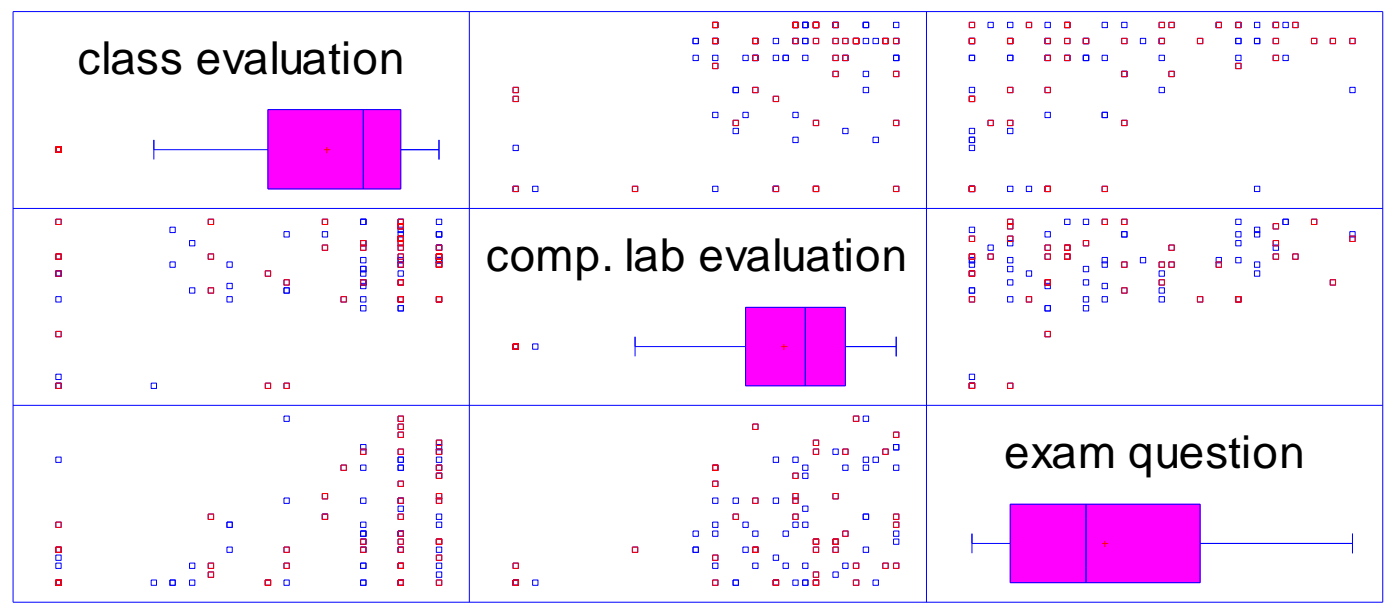

Figure 4. Scatterplots and box-whisker plots of the three evaluations results. 
In one group there is linear correlation between the students' results in the classroom activity and in the exam problem (Table 4). In the other group (Table 5) the correlation is significant between the three assessment activities marks. The average and median marks obtained in the exam regression question, is worse than in the classroom and computer laboratory tasks in both groups (Table 6).

Table 4. Pearson product moment correlations between assessment activities in group 1.

Correlations

class. evaluation comp.lab evaluation exam question

\begin{tabular}{lccc}
\hline & & 0,2559 & 0,4297 \\
class. evaluation & & $(43)$ & $(43)$ \\
& & 0,0976 & 0,0040 \\
comp.lab evaluation & 0,2559 & & 0,2560 \\
& $(43)$ & & $(43)$ \\
& 0,0976 & & 0,0976 \\
exam evaluation & 0,4297 & 0,2560 & \\
& $(43)$ & $(43)$ & \\
& 0,0040 & 0,0976 &
\end{tabular}

Correlation

(Sample Size)

P-Value

Table 5. Pearson product moment correlations between assessment activities in group 2 .

Correlations

class. evaluation comp.lab evaluation exam question

\begin{tabular}{|c|c|c|c|}
\hline class. evaluation & & $\begin{array}{l}0,5182 \\
\left(\begin{array}{c}50) \\
0,0001\end{array}\right.\end{array}$ & $\begin{array}{l}0,3845 \\
(50) \\
0,0058\end{array}$ \\
\hline comp.lab evaluation & $\begin{array}{l}0,5182 \\
\left(\begin{array}{c}50) \\
0,0001\end{array}\right.\end{array}$ & & $\begin{array}{l}0,4755 \\
\left(\begin{array}{c}50) \\
0,0005\end{array}\right.\end{array}$ \\
\hline exam evaluation & $\begin{array}{l}0,3845 \\
\left(\begin{array}{c}50) \\
0,0058\end{array}\right.\end{array}$ & $\begin{array}{l}0,4755 \\
\left(\begin{array}{c}50) \\
0,0005\end{array}\right.\end{array}$ & \\
\hline
\end{tabular}

Correlation

(Sample Size)

P-Value 
Table 6. Descriptive analysis of assessment activities marks in the two groups.

Summary Statistics. Class. evaluation

\begin{tabular}{lllll} 
Group & Number_students & Average & Median & $\begin{array}{l}\text { Standard } \\
\text { Deviation }\end{array}$ \\
\hline 1 & 43 & 7,12791 & 9,0 & 3,36667 \\
2 & 50 & 6,96 & 8,0 & 3,1507 \\
\hline Total & 93 & 7,03763 & 8,0 & 3,23553
\end{tabular}

Summary Statistics. Comp. lab evaluation

\begin{tabular}{lllll} 
Group & Students_number & Average & Median & $\begin{array}{l}\text { Standard } \\
\text { Deviation }\end{array}$ \\
\hline 1 & 43 & 6,72093 & 7,5 & 2,37748 \\
2 & 50 & 6,715 & 7,0 & 2,24575 \\
\hline Total & 93 & 6,71774 & 7,25 & 2,29491
\end{tabular}

Summary Statistics. Exam. evaluation

\begin{tabular}{lcccc} 
Group & Students_number & Average & Median & $\begin{array}{l}\text { Standard } \\
\text { Deviation }\end{array}$ \\
\hline 1 & 43 & 3,54651 & 2,5 & 3,07360 \\
2 & 50 & 3,46 & 3,0 & 2,91301 \\
\hline Total & 93 & 3,5 & 3,0 & 2,97224
\end{tabular}

\section{REFERENCES}

[1] ABET (2016). About ABET. Available on-line http://www.abet.org/about-abet/. (Date of access $8^{\text {th }}$ January 2016).

[2] Gal, I., Garfield, J. (1997). The assessment challenge in statistics education, IOS Press, The International Statistical Institute, The Netherlands.

[3] Jain, R. (1991). The art of computer systems performance analysis: Techniques for experimental design, measurement, simulation, and modeling. John Wiley \& Sons.

[4] Romero, R., Zúnica, L. (2013). Métodos estadísticos para ingenieros. Valencia, Spain. Polytechnic University Editorial.

[5] Box, G. E. P., Hunter. W.G., Hunter Stuart J. (2008). Estadística para investigadores: introducción al diseño de experimentos, análisis de datos y construcción de modelos. Reverté.

[6] Scheaffer, R.L., Gnanadesikan, M., Watkins, A., Witmer, J. (1996). Activity-Based Statistics. New York: Springer-Verlag.

[7] Zúnica, L.R., Romero, R. (1989). Un modelo para el control del consumo de energía en una industria automovilística. II Congreso de la Calidad en la Industria Energética. Santander, Spain.

[8] Vázquez, E. (2015) Práctica 9. Creative Commons license. http://creativecommons.org/licences/by-nc-sa/2.5/es. 
[9] Romero, R., Zúnica, L. (2008). Métodos estadísticos en ingeniería. Valencia, Spain. Polytechnic University Editorial. 